ENVIRONMENTAL EXPOSURE

\title{
Childhood exposure to environmental tobacco smoke and chronic respiratory symptoms in non- smoking adults: The Singapore Chinese Health Study
}

\author{
G L David, W-P Koh, H-P Lee, M C Yu, S J London
}

Thorax 2005;60:1052-1058. doi: 10.1136/thx.2005.042960

See end of article for authors' affiliations

\section{Correspondence to:}

Dr S J London, National Institute of Environmental Health Sciences, P O Box 12233, Mail Drop A3-05, Research Triangle Park, NC 27709, USA;

london2@niehs.nih.gov

Received 23 February 2005 Accepted 1 August 2005 Published Online First 30 August 2005

\begin{abstract}
Background: Childhood exposure to environmental tobacco smoke has been extensively associated with childhood respiratory illness; fewer studies have addressed the effects on adults.

Methods: Childhood environmental tobacco smoke exposure in relation to chronic cough, phlegm, and asthma diagnosis was studied in never smokers from a cohort of Singaporeans of Chinese ethnicity aged 45-74 years at enrolment from 1993 to 1998 . From 1999 to 2004 subjects were interviewed regarding environmental tobacco smoke exposure before and after the age of 18 and the presence and duration of current symptoms of chronic cough and phlegm production and asthma diagnosis.

Results: Among 35000 never smokers, fewer had smoking mothers (19\%) than fathers (48\%). Although few subjects currently lived $(20 \%)$ or worked $(4 \%)$ with smokers, $65 \%$ reported living with a daily smoker before the age of 18 years. Living with a smoker before the age of 18 increased the odds of chronic dry cough (149 cases, odds ratio $2.1,95 \% \mathrm{Cl} 1.4$ to 3.3 ) and, to a lesser extent, phlegm, after adjustment for age, sex, dialect group, and current and past exposure to smokers at home and at work after the age of 18. Associations strengthened with higher numbers of smokers in childhood. There was no association with asthma or chronic bronchitis. There was evidence to suggest a stronger association among subjects with a lower adult intake of fibre which has previously been found to be protective for respiratory symptoms.

Conclusions: In this large study of non-smokers, living with a smoker in childhood was associated with chronic dry cough and phlegm in adulthood, independent of later exposures to environmental tobacco smoke.
\end{abstract}

hildhood exposure to environmental tobacco smoke (ETS) has consistently been associated with childhood respiratory illness and symptoms including bronchitis, pneumonia, cough, phlegm, breathlessness, wheeze, and asthma (reviewed by Cook and Strachan ${ }^{1}$ ). Several studies have suggested that ETS exposure in adulthood is associated with non-malignant respiratory disease (reviewed by Jaakkola and Jaakkola ${ }^{2}$ ), but data on the relation between childhood exposure to ETS and non-malignant respiratory illness in adults are somewhat inconsistent. ${ }^{3-12}$ Most of these studies deal with asthma alone.

Findings on childhood ETS exposure in relation to adult respiratory symptoms and illnesses are probably confounded by the strong association between active smoking and these outcomes. Exposure to tobacco smoke in early life may influence smoking behaviour later in life. ${ }^{6}$ Of the studies with data on childhood ETS exposure and adult respiratory illness, most have a large proportion of smokers. A study of nonsmokers offers the advantage of virtually eliminating residual confounding by smoking. The usefulness of restricting the analysis to non-smokers in the elimination of bias due to uncontrollable confounding by active smoking has been demonstrated for the study of leanness in relation to lung

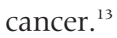

We examined whether exposure to ETS as a child increased the prevalence of adult chronic cough, phlegm, and asthma in a population of 35000 lifetime never smokers from the Singapore Chinese Health Study. We also considered whether the effects of childhood exposure to tobacco smoke in the home might be modified by intake of non-starch polysaccharides, a form of dietary fibre that is associated with reduced chronic respiratory symptoms in this cohort. ${ }^{14}$

\section{METHODS}

\section{Study population}

The design of the Singapore Chinese Health Study has been described previously. ${ }^{15}$ Briefly, the cohort was drawn from a population of men and women of Chinese ethnicity, aged 4574 years, who were permanent residents or citizens of Singapore and resided in government built housing estates which housed $86 \%$ of the population during the period of subject enrolment. The study was restricted to individuals belonging to the two major Chinese dialect groups in Singapore: Cantonese and Hokkien. Between April 1993 and December 1998 we enrolled 63257 individuals (85\% of those eligible). Baseline questionnaires were administered by trained interviewers in the subjects' homes and elicited information on demographics, active smoking, and medical history. The baseline interview included a 165-item quantitative food frequency questionnaire which was developed for and validated in this population, ${ }^{16}$ enabling estimation of intake of non-starch polysaccharides, a form of dietary fibre. ${ }^{14}$

Beginning in 1999, subjects were interviewed by telephone regarding active smoking, history of ETS exposure before and after age 18 , and the presence and duration of respiratory symptoms.

At 31 December 2004 there were 7722 deaths in the overall cohort. The follow up telephone interview was completed for 52325 individuals. The average time between the baseline and follow up interviews was 5.8 years. We restricted the analysis to the 35000 never smokers defined by a "no" response to the question at baseline about ever having smoked at least one cigarette a day for 1 year or longer and a further "no" response to the question "Have you smoked at least 100 cigarettes in your lifetime?" on the follow up 
interview. Smoking histories were not validated by biomarkers, but studies comparing serum cotinine data with selfreported tobacco use suggest that there is little misclassification of non-smokers based on self-reporting in surveys of the general population. ${ }^{17} 18$

American Thoracic Society questionnaire items (ATS-DLD78-A) were used to assess history of asthma, cough, and phlegm production (see Appendix 1 in online supplement available at http://www.thoraxjnl.com/supplemental). ${ }^{19}$ Because we were interested in the general question of whether early life exposure to smokers increased later risk of respiratory outcome, we wanted to compare these various outcomes with a common group of individuals who had no respiratory impairment. The subjects were therefore divided into mutually exclusive categories based on asthma, cough, and phlegm. "Chronic" was defined as occurring on most days for at least 3 months of the year, lasting for more than two consecutive years. We first classified subjects according to reports of doctor diagnosed asthma and then classified those without this report according to the presence of chronic cough and/or phlegm or, if these symptoms did not meet the definition of chronic, into a combined recent symptoms category. The categories were doctor-diagnosed asthma $(\mathrm{n}=1504$ cases $)$, recent cough and/or phlegm $(n=1320)$, chronic phlegm $(n=700)$, chronic cough $(\mathrm{n}=185)$, chronic cough plus phlegm (chronic bronchitis) $(\mathrm{n}=149)$, and a referent group with no cough, phlegm, or asthma $(\mathrm{n}=31 \quad 142)$.

The objective of this study was to examine the association between early life exposure to ETS and chronic respiratory symptoms in adults; analyses of the 1320 individuals reporting recent cough and/or phlegm are not therefore included in the tables for reasons of space but can be found in Appendix 2 in the online supplement available at http:// www.thoraxjnl.com/supplemental.

The protocol was reviewed and approved by the Institutional Review Boards of the University of Southern California, the National University of Singapore, and the US National Institute of Environmental Health Sciences.

\section{Statistical analysis}

We examined the odds of chronic respiratory symptoms in adults in relation to exposure to ETS in early life and adulthood. Odds ratios (ORs) and 95\% confidence intervals (CIs) were calculated from unconditional logistic regression models (SAS Version 9.0; SAS Institute, Cary, NC, USA).

Childhood exposure, defined as birth to age 18, was defined with a semi-quantitative variable representing the minimum number of smokers an individual lived with during childhood from the number of categories marked regarding who smoked in the household (father, mother, grandparent(s), sibling(s), and other person(s); see Appendix 1 in online supplement for questionnaire items). Some of the categories could include more than one smoker, so each marked category included at least one smoker. We created a similar semi-quantitative variable for residential exposure after age 18, henceforth referred to as "adult home exposure". Adult work exposure was modelled as past or current versus none.

All odds ratios were adjusted for age as a continuous variable, sex, and dialect group. The following covariates were assessed as potential confounders: education (completed $\leqslant$ grade 6 , grade $7-10$, grade 11 or higher), body mass index as a continuous variable (log transformed), occupation (10 categories), being born in Singapore versus elsewhere, and dietary intake of non-starch polysaccharides (quartiles). None appreciably changed the associations so they were not included in the multivariate models.

\section{RESULTS}

Women outnumbered men in this population of lifetime nonsmokers, which was expected given the lower smoking rates among women (table 1). Overall, 65\% of subjects reported living with at least one daily smoker before the age of 18 . Only 19\% reported maternal smoking; $48 \%$ reported paternal smoking. Adult home exposure to ETS and work exposure were more common in the past than currently (table 1). These trends reflect prohibitive measures against smoking in public places and health education efforts established in the

Table 1 Characteristics of the Singapore Chinese Health Study never smokers

\begin{tabular}{|c|c|c|c|c|c|c|c|}
\hline Characteristic & $\begin{array}{l}\text { No cough, phlegm } \\
\text { or asthma } \\
(\mathrm{N}=31142)\end{array}$ & $\begin{array}{l}\text { Recent cough } \\
\text { and/or phlegm } \\
(\mathrm{N}=1320)\end{array}$ & $\begin{array}{l}\text { Asthma } \\
\text { diagnosis } \\
(\mathrm{N}=1504)\end{array}$ & $\begin{array}{l}\text { Chronic } \\
\text { bronchitis* } \\
(\mathrm{N}=149)\end{array}$ & $\begin{array}{l}\text { Chronic phlegm } \\
\text { without cough } \\
(\mathrm{N}=700)\end{array}$ & $\begin{array}{l}\text { Chronic dry } \\
\text { cough } \\
(\mathrm{N}=185)\end{array}$ & $\begin{array}{l}\text { Total subjects } † \\
(\mathrm{~N}=35000)\end{array}$ \\
\hline$\%$ of totalt & 89.0 & 3.8 & 4.3 & 0.4 & 2.0 & 0.5 & 100 \\
\hline$\%$ female & 77.3 & 72.4 & 77.0 & 65.1 & 68.7 & 68.1 & 76.8 \\
\hline $\begin{array}{l}\text { Mean (SD) age (years) } \\
\text { Hokkien or Cantonese dialect }\end{array}$ & $60.7(7.8)$ & $61.5(8.1)$ & $60.2(7.8)$ & $62.1(8.0)$ & $60.1(7.9)$ & $60.7(7.4)$ & $60.7(7.8)$ \\
\hline $\begin{array}{l}\text { \% Hokkien } \\
\text { Childhood ETS exposure (\%) }\end{array}$ & 49.8 & 37.3 & 52.5 & 55.7 & 44.3 & 59.5 & 49.4 \\
\hline None & $35.4 \S$ & 29.5 & $31.4 \S$ & 24.2 & 26.1 & 19.5 & $34.7 \S$ \\
\hline 1 smoker $\ddagger$ & 34.0 & 35.8 & 34.2 & 39.6 & 35.1 & 40.5 & 34.2 \\
\hline 2 smokers & 21.4 & 24.1 & 24.1 & 22.1 & 25.9 & 27.6 & 21.7 \\
\hline 3+ smokers & 9.3 & 10.6 & 10.2 & 14.1 & 12.9 & 12.4 & 9.5 \\
\hline \multicolumn{8}{|l|}{ Adult ETS exposure (\%) } \\
\hline \multicolumn{8}{|l|}{ Home } \\
\hline None & 27.7 & 23.1 & $24.5 \S$ & $14.1 \S$ & 21.1 & $20.5 \S$ & 27.2 \\
\hline \multicolumn{8}{|l|}{ Past } \\
\hline 1 smoker & 30.7 & 32.0 & 28.3 & 35.6 & 34.7 & 35.7 & 30.8 \\
\hline $2+$ smokers & 21.4 & 23.6 & 24.9 & 26.2 & 23.6 & 27.6 & 21.7 \\
\hline \multicolumn{8}{|l|}{ Current } \\
\hline 1 smoker & 17.7 & 18.6 & 19.9 & 19.5 & 17.0 & 14.1 & 17.8 \\
\hline $\begin{array}{l}2+\text { smokers } \\
\text { Work }\end{array}$ & 2.5 & 2.7 & 2.5 & 4.7 & 3.6 & 2.2 & 2.5 \\
\hline None & 78.1 & 72.2 & 73.1 & $66.4 \S$ & $66.4 \S$ & 67.0 & 77.3 \\
\hline Past & 17.7 & 23.1 & 21.4 & 29.5 & 25.4 & 26.5 & 18.3 \\
\hline Current & 4.2 & 4.7 & 5.5 & 4.0 & 8.1 & 6.5 & 4.4 \\
\hline $\begin{array}{l}{ }^{*} \text { Chronic bronchitis was defin } \\
\text { †Total includes all } 35000 \text { no } \\
\ddagger \text { Number of smokers for child } \\
\S \text { Some percentages do not ac }\end{array}$ & $\begin{array}{l}\text { ombined chronic cc } \\
\text { ing subjects. } \\
\text { and adult ETS expos } \\
100 \text { because of } r\end{array}$ & $\begin{array}{l}\text { and phlegm. } \\
\text { s a semi-quanti } \\
\text { ng. }\end{array}$ & variable $r$ & enting the & number of sm & & \\
\hline
\end{tabular}


Table 2 Respiratory symptoms in relation to exposure to environmental tobacco smoke (ETS)

\begin{tabular}{|c|c|c|c|c|c|c|c|c|c|}
\hline & \multirow{2}{*}{$\begin{array}{l}\text { No cough, } \\
\text { phlegm or } \\
\text { asthma } \\
\mathrm{N}\end{array}$} & \multicolumn{2}{|c|}{ Asthma diagnosis } & \multicolumn{2}{|c|}{ Chronic bronchitis* } & \multicolumn{2}{|c|}{$\begin{array}{l}\text { Chronic phlegm without } \\
\text { cough }\end{array}$} & \multicolumn{2}{|c|}{ Chronic dry cough } \\
\hline & & $\mathbf{N}$ & OR $(95 \% \mathrm{Cl}) \dagger$ & $\mathrm{N}$ & OR $(95 \% \mathrm{Cl})$ & $\mathrm{N}$ & OR $(95 \% \mathrm{Cl})$ & $\mathbf{N}$ & OR $(95 \% \mathrm{Cl})$ \\
\hline \multicolumn{10}{|c|}{ Childhood home ETS exposureł } \\
\hline None & 11011 & 473 & 1.00 & 36 & 1.00 & 183 & 1.00 & 36 & 1.00 \\
\hline 1 smoker§ & 10599 & 515 & $1.06(0.92$ to 1.22$)$ & 59 & $1.21(0.76$ to 1.92$)$ & 246 & $1.18(0.95$ to 1.47$)$ & 75 & 2.07 (1.32 to 3.24$)$ \\
\hline 2 smokers & 6649 & 362 & $1.13(0.96$ to 1.32$)$ & 33 & 1.01 (0.59 to 1.73 ) & 181 & 1.33 (1.04 to 1.69$)$ & 51 & 2.24 (1.36 to 3.70$)$ \\
\hline $3+$ smokers & 2883 & 154 & $1.06(0.86$ to 1.31$)$ & 21 & $1.42(0.77$ to 2.63$)$ & 90 & 1.48 (1.10 to 1.99$)$ & 23 & 2.36 (1.29 to 4.32$)$ \\
\hline Ptrend & & & 0.317 & & 0.491 & & 0.004 & & 0.005 \\
\hline $1+$ smokers & 20131 & 1031 & 1.08 (0.94 to 1.23$)$ & 113 & 1.18 (0.76 to 1.82$)$ & 517 & 1.25 (1.02 to 1.53$)$ & 149 & 2.14 (1.39 to 3.29$)$ \\
\hline \multicolumn{10}{|c|}{ Adult home ETS exposure } \\
\hline None & 8635 & 369 & 1.00 & 21 & 1.00 & 148 & 1.00 & 38 & 1.00 \\
\hline 1 past smoker & 9558 & 425 & $0.98(0.83$ to 1.15$)$ & 53 & $2.13(1.22$ to 3.72$)$ & 243 & 1.30 (1.03 to 1.64$)$ & 66 & 1.04 (0.66 to 1.62$)$ \\
\hline $2+$ past smokers & 6655 & 374 & $1.22(1.02$ to 1.45$)$ & 39 & 2.37 (1.27 to 4.43$)$ & 165 & $1.26(0.96$ to 1.66$)$ & 51 & $1.06(0.63$ to 1.76$)$ \\
\hline $1+$ current smokers & 6294 & 336 & 1.16 (0.98 to 1.38$)$ & 36 & $2.69(1.46$ to 4.94$)$ & 144 & 1.33 (1.02 to 1.73 ) & 30 & 0.75 (0.44 to 1.30$)$ \\
\hline ptrend & & & 0.017 & & 0.005 & & 0.099 & & 0.285 \\
\hline Past or current & 22507 & 1135 & 1.07 (0.93 to 1.24$)$ & 128 & 2.30 (1.36 to 3.91$)$ & 552 & 1.30 (1.04 to 1.62$)$ & 147 & 0.97 (0.64 to 1.49 ) \\
\hline \multicolumn{10}{|l|}{ Work ETS exposure ${ }^{\star *}$} \\
\hline None & 24325 & 1099 & 1.00 & 99 & 1.00 & 465 & 1.00 & 124 & 1.00 \\
\hline Past or current & 6817 & 405 & 1.30 (1.15 to 1.47$)$ & 50 & 1.51 (1.05 to 2.17$)$ & 235 & 1.55 (1.31 to 1.83$)$ & 61 & $1.53(1.10$ to 2.11$)$ \\
\hline $\begin{array}{l}\text { *Chronic bronchitis wa } \\
\text { †All odds ratios (OR) } \\
\text { †ORs adjusted for adu } \\
\text { §Number of smokers } \\
\text { "ORs adjusted for chil } \\
{ }^{* *} \text { ORs adjusted for chil }\end{array}$ & $\begin{array}{l}\text { s combined c } \\
\text { nfidence inte } \\
1 \text { past, } 2+ \\
d \text { and adult } \\
1,2,3+\text { smo } \\
1,2,3+\text { smc }\end{array}$ & $\begin{array}{l}\text { ast, 1+ } \\
\text { TS expos } \\
\text { kers) an }\end{array}$ & $\begin{array}{l}\text { ugh and phlegm. } \\
\text { are adjusted for age, s } \\
\text { current smokers) and w } \\
\text { ure is a semi-quantitati } \\
\text { work (no, past or curr }\end{array}$ & $\begin{array}{l}x, \text { and } \\
\text { rk (no, } \\
\text { e varia } \\
\text { ent) exp } \\
t 2+p c\end{array}$ & $\begin{array}{l}\text { dialect group plus ETS } \\
\text { past or current) expost } \\
\text { ble representing the mi } \\
\text { osure. } \\
\text { ast, } 1+\text { current smokers }\end{array}$ & $\begin{array}{l}\text { variab } \\
\text { re. } \\
\text { imum }\end{array}$ & $\begin{array}{l}\text { les as indicated in sub } \\
\text { number of smokers. } \\
\text { ure. }\end{array}$ & quer & otnotes. \\
\hline
\end{tabular}

1970s in Singapore. ${ }^{20}{ }^{21}$ Chronic dry cough was reported by $0.5 \%$ of subjects and chronic phlegm without cough by $2 \%$.

Subjects who lived with one or more daily smokers before the age of 18 had increased odds of chronic phlegm without cough (OR 1.25, 95\% CI 1.02 to 1.53 ) and chronic dry cough (OR 2.14, 95\% CI 1.39 to 3.29; table 2). We observed a significant trend of increasing odds ratios with higher number of smokers in the household in early life for both chronic phlegm $\left(p_{\text {trend }}=0.004\right)$ and chronic dry cough $\left(\mathrm{p}_{\text {trend }}=0.005\right)$. We were unable to examine dose-response with duration of early life exposure because duration varied little; $91 \%$ of the subjects who reported exposure before the age of 18 indicated a duration of 12 or more years, the top category. Early life ETS exposure was associated with chronic bronchitis when adjusting only for age, sex, and dialect (OR $1.78,95 \%$ CI 1.22 to 2.61 ); adjustment for exposure after age 18 virtually eliminated the association (OR 1.18, 95\% CI 0.76 to 1.82). Chronic phlegm production alone gave similar

Table 3 Respiratory symptoms in relation to environmental tobacco smoke (ETS) exposure in men and women

\begin{tabular}{|c|c|c|c|c|c|c|c|c|c|}
\hline & \multirow{2}{*}{$\begin{array}{l}\text { No cough, } \\
\text { phlegm or } \\
\text { asthma } \\
\mathrm{N}\end{array}$} & \multicolumn{2}{|c|}{ Asthma diagnosis } & \multicolumn{2}{|c|}{ Chronic bronchitis* } & \multicolumn{2}{|c|}{$\begin{array}{l}\text { Chronic phlegm without } \\
\text { cough }\end{array}$} & \multicolumn{2}{|c|}{ Chronic dry cough } \\
\hline & & $\mathbf{N}$ & OR $(95 \% \mathrm{Cl}) \dagger$ & $\mathbf{N}$ & OR $(95 \% \mathrm{Cl})$ & $\mathbf{N}$ & OR $(95 \% \mathrm{Cl})$ & $\mathbf{N}$ & OR $(95 \% \mathrm{Cl})$ \\
\hline \multicolumn{10}{|c|}{$\operatorname{Men}(N=7759)$} \\
\hline \multicolumn{10}{|c|}{ Childhood home ETS exposure $\neq$} \\
\hline None & 2292 & 112 & 1.00 & 11 & 1.00 & 50 & 1.00 & 11 & 1.00 \\
\hline 1+ smokers§ & 4791 & 234 & $0.82(0.60$ to 1.13$)$ & 41 & 0.93 (0.39 to 2.23$)$ & 169 & $1.40(0.92$ to 2.11$)$ & 48 & 2.24 (1.00 to 5.03$)$ \\
\hline \multicolumn{10}{|c|}{ Adult home ETS exposure } \\
\hline None & 2862 & 129 & 1.00 & 11 & 1.00 & 70 & 1.00 & 19 & 1.00 \\
\hline Past or current & 4221 & 217 & 1.27 (0.94 to 1.72$)$ & 41 & $2.52(1.06$ to 6.00$)$ & 149 & $1.16(0.80$ to 1.68$)$ & 40 & 0.87 (0.44 to 1.71$)$ \\
\hline \multicolumn{10}{|c|}{ Work ETS exposure ** } \\
\hline None & 4229 & 195 & 1.00 & 25 & 1.00 & 112 & 1.00 & 32 & 1.00 \\
\hline Past or current & 2854 & 151 & 1.15 (0.92 to 1.43$)$ & 27 & 1.46 (0.84 to 2.53$)$ & 107 & 1.35 (1.03 to 1.77$)$ & 27 & $1.16(0.69$ to 1.94$)$ \\
\hline \multicolumn{10}{|c|}{ Women $(N=25921)$} \\
\hline \multicolumn{10}{|c|}{ Childhood home ETS exposure } \\
\hline None & 8719 & 361 & 1.00 & 25 & 1.00 & 133 & 1.00 & 25 & 1.00 \\
\hline $1+$ smokers§ & 15340 & 797 & $1.17(1.01$ to 1.36$)$ & 72 & $1.27(0.77$ to 2.10$)$ & 348 & $1.21(0.96$ to 1.52$)$ & 101 & $2.16(1.31$ to 3.55$)$ \\
\hline \multicolumn{10}{|c|}{ Adult home ETS exposure } \\
\hline None & 5773 & 240 & 1.00 & 10 & 1.00 & 78 & 1.00 & 19 & 1.00 \\
\hline Past or current & 18286 & 918 & $1.06(0.90$ to 1.25$)$ & 87 & 2.34 (1.15 to 4.76$)$ & 403 & 1.43 (1.09 to 1.88 ) & 107 & $1.09(0.63$ to 1.88$)$ \\
\hline \multicolumn{10}{|c|}{ Work ETS exposure ${ }^{* *}$} \\
\hline None & 20096 & 904 & 1.00 & 74 & 1.00 & 353 & 1.00 & 92 & 1.00 \\
\hline Past or current & 3963 & 254 & 1.40 (1.21 to 1.62$)$ & 23 & 1.60 (0.99 to 2.57 ) & 128 & 1.70 (1.38 to 2.09 ) & 34 & 1.86 (1.25 to 2.78$)$ \\
\hline $\begin{array}{l}\text { *Chronic bronchit } \\
\text { †All ORs are adju } \\
\text { ‡ORs adjusted for } \\
\text { \$Number of smok } \\
\text { ๆORs adjusted for } \\
{ }^{* *} \text { ORs adjusted fo }\end{array}$ & $\begin{array}{l}\mathrm{d} \text { as combine } \\
\text { and dialect g } \\
\text { (no, past or c } \\
\text { nood ETS expc } \\
\text { no, } 1+\text { smoke } \\
\text { no, } 1+\text { smoke }\end{array}$ & $\begin{array}{l}\text { roup. } \\
\text { urrent) } \\
\text { osure is } \\
\text { rs) and } \\
\text { rs) and }\end{array}$ & $\begin{array}{l}\text { cough and phlegm. } \\
\text { d work (no, past or cu } \\
\text { semi-quantitative varia } \\
\text { rk (no, past or current } \\
\text { lult home (no, past or }\end{array}$ & $\begin{array}{l}\text { rent) } \\
\text { ble re } \\
\text { exp }\end{array}$ & $\begin{array}{l}\text { sure. } \\
\text { posing the minimum nu }\end{array}$ & mber $c$ & nokers. & & \\
\hline
\end{tabular}


Table 4 Chronic phlegm and chronic cough in relation to childhood exposure to environmental tobacco smoke (ETS) stratified by fibre intake*

\begin{tabular}{|c|c|c|c|c|c|}
\hline & \multirow{2}{*}{$\begin{array}{l}\text { No cough, } \\
\text { phlegm or } \\
\text { asthma }\end{array}$} & \multicolumn{2}{|c|}{ Chronic phlegm } & \multicolumn{2}{|c|}{ Chronic cough } \\
\hline & & $\mathrm{N}$ & OR $(95 \%$ Cl)† & $\mathrm{N}$ & OR $(95 \% \mathrm{Cl})$ \\
\hline \multicolumn{6}{|c|}{$\begin{array}{l}\text { Fibre intake below the median } \\
\text { Childhood home ETS exposure }\end{array}$} \\
\hline None & 4616 & 75 & 1.00 & 12 & 1.00 \\
\hline 1 smoker & 4453 & 100 & $1.28(0.91$ to 1.80$)$ & 34 & $3.12(1.51$ to 6.46$)$ \\
\hline 2 smokers & 2891 & 72 & 1.38 (0.94 to 2.02$)$ & 30 & $4.59(2.13$ to 9.90$)$ \\
\hline $3+$ smokers & 1247 & 49 & 2.13 (1.38 to 3.27$)$ & 13 & $4.99(2.03$ to 12.25$)$ \\
\hline 1+ smokers & 8591 & 221 & $1.39(1.01$ to 1.90$)$ & 77 & $3.63(1.82$ to 7.27$)$ \\
\hline \multicolumn{6}{|c|}{$\begin{array}{l}\text { Fibre intake above the median } \\
\text { Childhood home ETS exposure }\end{array}$} \\
\hline None & 6395 & 108 & 1.00 & 24 & 1.00 \\
\hline 1 smoker & 6146 & 146 & 1.11 (0.84 to 1.48$)$ & 41 & $1.54(0.86$ to 2.74$)$ \\
\hline 2 smokers & 3758 & 109 & $1.28(0.94$ to 1.76$)$ & 21 & $1.18(0.59$ to 2.36$)$ \\
\hline 3+ smokers & 1636 & 41 & 1.08 (0.72 to 1.63 ) & 10 & 1.25 (0.53 to 2.93$)$ \\
\hline 1+ smokers & 11540 & 296 & $1.16(0.89$ to 1.51$)$ & 72 & $1.41(0.81$ to 2.48$)$ \\
\hline
\end{tabular}

*Fibre is estimated by non-starch polysaccharide intake.

†Odds ratios adjusted for age, dialect group, sex and adult home exposure (no, 1 past, 2+ past, 1+ current smokers) and work exposure (none $v$ past or current).

$\ddagger$ Median in the entire Singapore Chinese cohort of calorie adjusted non-starch polysaccharide intake $=7.5 \mathrm{~g} /$ day.

results to chronic bronchitis for early ETS. If these two categories are combined, the OR for living with a smoker before the age of 18 was 1.24 (95\% CI 1.03 to 1.49 ). In the overall data we found no appreciable relationship between early life ETS exposure and doctor diagnosed asthma.

Chronic cough was equally strongly associated with early life exposure to maternal smoking (OR 2.22, 95\% CI 1.33 to 3.69) and with early life exposure to smoking by others including father, grandparent, sibling, other (OR 2.11, 95\% CI 1.36 to 3.28; see Appendix 3 in online supplement available at http://www.thoraxjnl.com/supplemental). Smoking by mothers alone was uncommon (4\%) in this population.

Although some of the categories become sparse, because of previous literature, ${ }^{10}$ we examined the effects of parental smoking on adult respiratory health by sex (table 3). ETS exposure in early life was similarly associated with an increased risk of chronic dry cough in women and men, although precision was lower in the smaller stratum of men. Living with at least one smoker in childhood raised the odds of doctor-diagnosed asthma in women (OR 1.17, 95\% CI 1.01 to 1.36 ) but not in men (OR $0.82,95 \%$ CI 0.60 to 1.13 ; p value for difference $=0.05$ ) .

No appreciable difference was seen in the association between early life exposure and chronic dry cough by age $(</$ $\geqslant$ median of 61 years) or dialect group (data not shown).

We also examined possible effect modification of the association between early ETS exposure and chronic cough or phlegm by intake of non-starch polysaccharides, a form of fibre related to reduced chronic respiratory symptoms in this cohort. ${ }^{14}$ Only potential effect modification by fibre was examined because we previously found that fibre intake explained univariate associations with antioxidant micronutrients (such as vitamin C, vitamin E, and carotenoids) and food groups such as total fruit and soyfoods. ${ }^{14}$ Although numbers become small on stratification, the association between early life ETS exposure and chronic dry cough or chronic phlegm was somewhat greater in subjects with a calorie adjusted intake of fibre below the median of $7.5 \mathrm{~g} /$ day for the entire Singapore Chinese cohort than in subjects with a higher intake (table 4). There was a significant trend with increasing number of smokers in childhood in the lower fibre $(\mathrm{p}<0.01)$ but not the higher fibre category for both chronic phlegm $\left(p_{\text {interaction }}=0.27\right)$ and chronic cough $\left(p_{\text {interaction }}\right.$ $=0.05$ ).

Adult ETS exposure at home was associated with various respiratory outcomes, independently of childhood exposure and adult work exposure. Adult past and current home exposure were positively associated with chronic bronchitis (table 2). Doctor diagnosed asthma was weakly related to exposure to two or more past smokers; a smaller association for currently living with one or more smokers might reflect the influence of an asthmatic on smoking behaviour of household members. The similar association of past and current exposure with the outcomes could reflect resistance to the effect of ETS on the part of persons still living with smokers after many years. Chronic phlegm, but not chronic

Table 5 Respiratory symptoms in relation to environmental tobacco smoke (ETS) exposure during early life and adulthood

\begin{tabular}{|c|c|c|c|c|c|c|c|c|c|}
\hline \multirow[b]{2}{*}{ ETS exposure } & \multirow{2}{*}{$\begin{array}{l}\text { No } \\
\text { cough, } \\
\text { phlegm } \\
\text { or } \\
\text { asthma } \\
\mathrm{N}\end{array}$} & \multicolumn{2}{|c|}{ Asthma diagnosis } & \multicolumn{2}{|c|}{ Chronic bronchitis* } & \multicolumn{2}{|c|}{$\begin{array}{l}\text { Chronic phlegm without } \\
\text { cough }\end{array}$} & \multicolumn{2}{|c|}{ Chronic dry cough } \\
\hline & & $\mathbf{N}$ & OR $(95 \% \mathrm{Cl}) \dagger$ & $\mathrm{N}$ & OR $(95 \% \mathrm{Cl})$ & $\mathrm{N}$ & OR $(95 \% \mathrm{Cl})$ & $\mathbf{N}$ & OR $(95 \% \mathrm{Cl})$ \\
\hline No childhood or adult exposuref & 5461 & 214 & 1.00 & 12 & 1.00 & 61 & 1.00 & 14 & 1.00 \\
\hline Childhood only & 1560 & 55 & $0.89(0.66$ to 1.21$)$ & 3 & $0.89(0.25$ to 3.14$)$ & 30 & 1.62 (1.04 to 2.52$)$ & 16 & 4.03 (1.96 to 8.29$)$ \\
\hline Adult only & 5550 & 259 & $1.19(0.99$ to 1.43$)$ & 24 & 2.06 (1.03 to 4.12$)$ & 122 & 2.11 (1.55 to 2.88$)$ & 22 & 1.57 (0.80 to 3.08$)$ \\
\hline Both child and adult & 18571 & 976 & 1.32 (1.13 to 1.53 ) & 110 & $2.87(1.58$ to 5.22$)$ & 487 & 2.38 (1.82 to 3.12$)$ & 133 & 2.80 (1.61 to 4.87$)$ \\
\hline
\end{tabular}

${ }^{*}$ Chronic bronchitis was defined as combined chronic cough and phlegm.

†All odds ratios (OR) and $95 \%$ confidence intervals are adjusted for age, sex, and dialect.

†Adult exposure includes home and/or work exposure. 
dry cough, was modestly associated with adult exposure to smokers in the home.

Exposure to ETS at work was associated with an increased risk for all outcomes after adjusting for adult home exposure and childhood exposure, with the weakest association being observed for asthma (table 2). We combined the small category of current work exposure with the larger past exposure category because odds ratios were in the same direction.

We explored the potential interaction between early life and adult ETS exposure and adult respiratory symptoms by examining odds ratios according to four categories of joint exposure: none, childhood only, adult only, and both childhood and adult. Although small numbers preclude precise estimation of the effects of exposure only in childhood, the associations with all outcomes were greater for exposure in both childhood and adulthood than for adult exposure alone (table 5). Stronger associations observed in table 5 compared with table 2 most likely reflect the fact that subjects in the reference category for table 5 had neither childhood nor adult ETS exposure.

We preferred mutually exclusive categories to compare each outcome group with the same reference category of individuals unaffected by any of the conditions. However, for comparison with studies that do not use mutually exclusive categories, we also compared each outcome group with all other subjects. Not surprisingly, the results were quite similar. For example, the odds ratio for living with a smoker before the age of 18 and chronic cough was 2.12 (95\% CI 1.38 to 3.26) and for chronic phlegm was 1.24 (95\% CI 1.01 to 1.52 ).

\section{DISCUSSION}

These data provide evidence that early life exposure to ETS has long term effects on adult respiratory health. Living with a smoker in childhood was associated with chronic dry cough and, to a lesser degree, phlegm production in adult nonsmokers, independently of later life exposures to ETS at home and at work. We observed a dose-response relationship with increasing odds ratios for higher estimated numbers of smokers in the home in childhood. These associations suggest effects of postnatal exposure given the low rates of maternal smoking in this population. We also found some evidence that intake of fibre might modify the association between early life ETS and adult respiratory symptoms.

It is unclear how early life exposure to ETS contributes to adult chronic dry cough. However, exposure to tobacco smoke in childhood may lead to permanent structural changes in the lung. Elliot et $a^{22}$ observed an increase in inner airway wall thickness of the larger airways in sudden infant death syndrome (SIDS) victims whose mothers smoked prenatally and postnatally compared with unexposed SIDS infants. In a larger subsequent study, significant inner wall thickening was seen in infants exposed only postnatally. ${ }^{23}$ This finding is relevant to our study where relatively few subjects would have had prenatal exposure. A small increase in airway wall thickness may contribute to excessive airway narrowing in response to smooth muscle contraction. ${ }^{24}$ Although studies in SIDS infants do not allow one to conclude whether the observed changes would have been permanent, lung function studies in adults provide suggestive evidence of long lasting damage to airways from childhood exposure. ${ }^{10-12}$

Exposure to ETS during childhood may also enhance the excitability of the sensory nerves of the lung that are responsible for the cough reflex. Exposure of guinea pigs to ETS in the first 5 weeks of life (equivalent of human childhood) upregulates lung C-fibre central nervous system (CNS) reflex responses which could result in cough. ${ }^{25}$ It is not known if these changes persist long term. Alternatively, ETS exposure during childhood may influence adult respiratory symptoms via the well documented increased risk of acute lower respiratory illness. ${ }^{1}$

Early life exposure to ETS was weakly associated with adult chronic phlegm without cough. One would expect that cough would accompany phlegm as subjects were asked to exclude phlegm from the nose. Few other studies using similar questions have reported separate results for phlegm, so it is hard to know the worldwide prevalence of reports of phlegm without cough. However, some other cohorts have also reported a higher prevalence of phlegm than of cough. ${ }^{26-29}$ In our cohort about twice as many people reported phlegm only compared with cough or cough with phlegm. This might reflect practices in Chinese populations in which spitting of phlegm onto the street is a common problem. ${ }^{30}$ Recognition of this habit resulted in the banning of public spitting in Singapore long ago. Ignoring phlegm from the nose in reporting may be difficult, especially in certain populations. We therefore present the chronic phlegm and chronic bronchitis outcomes separately. Results for early ETS were similar for the two outcomes although results for later ETS exposure differed somewhat. It is also possible that an increase in lung C-fibre CNS reflex responses to postnatal ETS exposure could lead to mucus hypersecretion and thus phlegm production. ${ }^{25}$

Data on early life exposure to ETS and adult respiratory symptoms or illness ${ }^{3-10}$ are not entirely consistent. In contrast with our study, most other studies examined only asthma. ${ }^{3-6} 89$ No association between childhood ETS exposure and asthma was observed in five studies; ${ }^{357810}$ positive associations were found in three others. ${ }^{469}$ We found weak evidence for an association between early life ETS and asthma only in women. Of note, in the study of Larsson et al, ${ }^{6}$ no association was found in subjects aged 40-69 years in the mid 1990s, a group of comparable birth cohort to our subjects. In the European Community Respiratory Health Survey (ECRHS) ${ }^{10}$ parental smoking was associated with wheeze, with a composite variable of three or more asthma symptoms, and with chronic bronchitis, but not with current asthma. Unfortunately, we did not ask about wheeze. We did not observe an association with chronic bronchitis after adjusting for later life ETS exposure. Robbins et al also found no association between childhood exposure and chronic bronchitis.

The major limitation of this cross sectional study is the potential for recall bias if individuals with respiratory symptoms are more likely to report ETS exposure. However, it seems reasonable that adults could remember if they lived with a smoker during childhood, especially after the age of 6 years. Data from the Midspan family study show that there is good agreement between parental reporting of maternal and paternal smoking and adult recall by offspring aged 3059 years. ${ }^{31}$ Furthermore, if recall bias has a major role, we would expect to see associations between early life exposure to ETS and all outcomes, not just chronic dry cough and phlegm. In the ECRHS, differential recall bias would not explain the finding that parental smoking during childhood was associated with reduced lung function even in nonsymptomatic subjects. ${ }^{10}$ We did not ask about childhood exposure to ETS sources outside of the home as the accuracy of these data is less certain.

This study enhances the existing literature which is based mostly on Western populations. Our Chinese population also provides a large proportion of non-smoking women. Restricting the analysis to non-smokers virtually eliminates potential confounding by active smoking. This is also the largest study of adult respiratory effects of early exposure to ETS.

A strength of this study is the high quality dietary data that enabled us to examine possible confounding and effect 
modification by intake of non-starch polysaccharides, the major protective factor for respiratory symptoms in this cohort. ${ }^{14}$ To our knowledge, this is the first study of childhood exposure to ETS to include examination of interaction by dietary factors. The dietary data were collected on the baseline questionnaire and thus were prospective with respect to the respiratory outcomes, eliminating the possibility of recall bias. We found suggestive evidence of a stronger association between chronic cough and phlegm and living with smokers in childhood among subjects with a lower intake of non-starch polysaccharides, a form of dietary fibre. Fibre is a complex dietary mixture ${ }^{32}$ that may have beneficial effects on the lung by reducing blood glucose concentrations, ${ }^{34-36}$ reducing inflammation, ${ }^{37}$ and enhancing antioxidant processes. ${ }^{38}{ }^{39}$ Higher fibre intake may produce a state of lower inflammation and oxidative stress that may protect the lung against subsequent environmental insults which could trigger development of respiratory symptoms among those exposed to ETS in childhood. Our data suggest that poorer diet might accentuate the deleterious effects of early life exposure to ETS. It is extremely difficult to obtain data on childhood diet from older adult subjects, so we are unable to test directly the possibility that adults with higher fibre intake also had higher fibre intake as children.

In conclusion, substantial evidence already exists that exposure to ETS in early life has adverse effects on childhood respiratory health. Our data from the Singapore Chinese Health Study add to a growing body of evidence that early life exposure may also adversely affect adult respiratory health. In this largest study to date, exposure (which was largely postnatal) was associated with chronic respiratory symptoms in adults. These results have major health implications given the widespread exposure of youth to ETS. In addition, other early life exposures such as outdoor air pollution may act through similar pathways resulting in long term consequences on respiratory health. These results emphasise the importance of reducing the exposure of children to tobacco smoke and other environmental pollutants.

\section{ACKNOWLEDGEMENTS}

The authors thank Siew-Hong Low of the National University of Singapore for supervising the fieldwork of the Singapore Chinese Health Study; Kazuko Arakawa of the University of Southern California for the development and management of the cohort study database; Marsha Shepherd of Westat Inc for programming; and Drs Donna Baird, Darryl C Zeldin, Eric Westman, and Elizabeth DeLong for helpful suggestions during preparation of this manuscript.

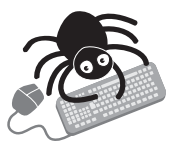

Appendices 1-3 are available online at http:// www.thoraxinl.com/supplemental.

\section{Authors' affiliations}

G L David, S J London, Epidemiology Branch, National Institute of Environmental Health Sciences, National Institutes of Health, Department of Health and Human Services, Research Triangle Park, NC, USA W-P Koh, H-P Lee, Yong Loo Lin School of Medicine, National University of Singapore, Singapore

M C Yu, University of Minnesota Cancer Center, Minneapolis, MN, USA This research was funded by the US National Cancer Institute (NCI ROI CA80205) and the Division of Intramural Research, US National Institute of Environmental Health Sciences (ZO1 ES43012).

Competing interests: none.

\section{REFERENCES}

1 Cook DG, Strachan DP. Health effects of passive smoking - 10: Summary of effects of parental smoking on the respiratory health of children and implications for research. Thorax 1999;54:357-66.
2 Jaakkola MS, Jaakkola JJ. Effects of environmental tobacco smoke on the respiratory health of adults. Scand J Work Environ Health 2002;28(Suppl 2):52-70.

3 De Marco R, Pattaro C, Locatelli F, et al. Influence of early life exposures on incidence and remission of asthma throughout life. J Allergy Clin Immunol 2004; 113:845-52.

4 Hu FB, Persky V, Flay BR, et al. An epidemiological study of asthma prevalence and related factors among young adults. J Asthma 1997;34:67-76.

5 Jenkins MA, Hopper JL, Bowes G, et al. Factors in childhood as predictors of asthma in adult life. BMJ 1994;309:90-3.

6 Larsson ML, Frisk M, Hallstrom J, et al. Environmental tobacco smoke exposure during childhood is associated with increased prevalence of asthma in adults. Chest $2001 ; 120: 711-7$

7 Robbins AS, Abbey DE, Lebowitz MD. Passive smoking and chronic respiratory disease symptoms in non-smoking adults. Int J Epidemiol 1993:22:809-17.

8 Sears MR, Greene JM, Willan AR, et al. A longitudinal, population-based, cohort study of childhood asthma followed to adulthood. N Engl J Med 2003;349:1414-22.

9 Strachan DP, Butland BK, Anderson HR. Incidence and prognosis of asthma and wheezing illness from early childhood to age 33 in a national British cohort. BMJ 1996;312:1195-9

10 Svanes C, Omenaas E, Jarvis D, et al. Parental smoking in childhood and adult obstructive lung disease: results from the European Community Respiratory Health Survey. Thorax 2004;59:295-302.

11 Upton MN, Watt GC, Davey Smith G, et al. Permanent effects of maternal smoking on offsprings' lung function. Lancet 1998;352:453.

12 Masi MA, Hanley JA, Ernst $P$, et al. Environmental exposure to tobacco smoke and lung function in young adults. Am Rev Respir Dis 1988; 138:296-9.

13 Henley SJ, Flanders WD, Manatunga A, et al. Leanness and lung cancer risk: fact or artifact? Epidemiology 2002;13:268-76.

14 Butler LM, Koh WP, Lee HP, et al. Dietary fiber and reduced cough with phlegm: a cohort study in Singapore. Am J Respir Crit Care Med 2004; 170:279-87.

15 Yuan JM, Stram DO, Arakawa K, et al. Dietary cryptoxanthin and reduced risk of lung cancer: the Singapore Chinese Health Study. Cancer Epidemiol Biomarkers Prev 2003;12:890-8.

16 Hankin JH, Stram DO, Arakawa K, et al. Singapore Chinese Health Study: development, validation, and calibration of the quantitative food frequency questionnaire. Nutr Cancer 2001;39:187-95.

17 Pirkle JL, Flegal KM, Bernert JT, et al. Exposure of the US population to environmental tobacco smoke: the Third National Health and Nutrition Examination Survey, 1988 to 1991. JAMA 1996;275:1233-40.

18 Vartiainen E, Seppala T, Lillsunde $P$, et al. Validation of self reported smoking by serum cotinine measurement in a community-based study. J Epidemiol Community Health 2002;56:167-70.

19 Ferris BG. Epidemiology standardization project (American Thoracic Society). Am Rev Respir Dis 1978;118:1-120.

20 Emmanuel SC, Chen AJ, Phe A. Cigarette smoking in Singapore. Singapore Med J 1988;29:119-24

21 Emmanuel SC, Phe A, Chen AJ. The impact of the anti-smoking campaign in Singapore. Singapore Med J 1988;29:233-9.

22 Elliot J, Vullermin P, Robinson P. Maternal cigarette smoking is associated with increased inner airway wall thickness in children who die from sudden infant death syndrome. Am J Respir Crit Care Med 1998; 158:802-6.

23 Elliot JG, Carroll NG, James AL, et al. Airway alveolar attachment points and exposure to cigarette smoke in utero. Am J Respir Crit Care Med 2003;167:45-9.

24 Moreno RH, Hogg JC, Pare PD. Mechanics of airway narrowing. Am Rev Respir Dis 1986;133:1171-80.

25 Bonham AC, Chen CY, Mutoh T, et al. Lung C-fiber CNS reflex: role in the respiratory consequences of extended environmental tobacco smoke exposure in young guinea pigs. Environ Health Perspect 2001;109/Suppl 4):573-8.

26 Levenberger $\mathbf{P}$, Schwartz J, Ackermann-Liebrich U, et al. Passive smoking exposure in adults and chronic respiratory symptoms (SAPALDIA study). Swiss Study on Air Pollution and Lung Diseases in Adults, SAPALDIA Team. Am J Respir Crit Care Med 1994;150:1222-8.

27 Rautalahti M, Virtamo J, Haukka J, et al. The effect of alpha-tocopherol and beta-carotene supplementation on COPD symptoms. Am J Respir Crit Care Med 1997;156:1447-52.

28 Zemp E, Elsasser S, Schindler C, et al. Long-term ambient air pollution and respiratory symptoms in adults (SAPALDIA study). The SAPALDIA Team. Am J Respir Crit Care Med 1999;159:1257-66.

29 Dalphin JC, Dubiez A, Monnet E, et al. Prevalence of asthma and respiratory symptoms in dairy farmers in the French province of the Doubs. Am J Respir Crit Care Med 1998;158:1493-8.

30 Mackenzie H. Why a SARS spitting ban is catching in throats of Chinese. Sunday Herald 25 May 2003. Available at http://www.sundayherald.com/ 34076

31 Upton MN. Effects of parental smoking on the respiratory health of adults. Thorax 2004;59:274-6.

32 Anon. Dietary reference intakes: proposed definition of dietary fiber. Washington, DC: National Academy Press, 2001.

33 Lee SC, Prosky L. International survey on dietary fiber: definition, analysis, and reference materials. J AOAC Int 1995;78:22-36. 
34 Walter RE, Beiser A, Givelber RJ, et al. Association between glycemic state and lung function: the Framingham Heart Study. Am J Respir Crit Care Med 2003; 167:911-6.

35 Eliraz A, Sternfeld M, Madar Z. Glycaemic and insulinaemic index of meals in stable obstructive pulmonary disease subjects. Eur J Clin Nutr 1994:48:522-4.

36 Davis WA, Knuiman M, Kendall P, et al. Glycemic exposure is associated with reduced pulmonary function in type 2 diabetes: the Fremantle Diabetes Study. Diabetes Care 2004;27:752-7.
37 Liu S, Manson JE, Buring JE, et al. Relation between a diet with a high glycemic load and plasma concentrations of high-sensitivity $\mathrm{C}$-reactive protein in middle-aged women. Am J Clin Nutr 2002;75:492-8.

38 Eastwood MA. Interaction of dietary antioxidants in vivo: how fruit and vegetables prevent disease? Q J Med 1999:92:527-30.

39 Larrauri JA, Goni I, Martin-Carron N, et al. Measurement of health-promoting properties in fruit dietary fibres: antioxidant capacity, fermentability and glucose retardation index. J Sci Food Agric 1996;71:515-9.

\section{LUNG ALERT}

Smoking reduction may lead to decreased lung cancer risk

A Godtfredsen NS, Prescott E, Osler M. Effect of smoking reduction on lung cancer risk. JAMA 2005;294:1505-10

S

ince many smokers are unable or unwilling to totally quit smoking, the concept of harm reduction is raised. This study, with up to 31 years of follow up, studied the smoking habits of 11151 men and 8563 women aged between 20 and 93 years. 864 cases of primary lung cancer occurred during follow up. Study participants were classified as heavy smokers ( $\geqslant 15 \mathrm{~g} /$ day), light smokers ( $1-14 \mathrm{~g} /$ day), ex-smokers, and never smokers. Consumption was calculated by equating a cigarette to $1 \mathrm{~g}$ of tobacco, a cheroot to $3 \mathrm{~g}$, and a cigar to $5 \mathrm{~g}$. Smoking reduction was defined as a reduction of $50 \%$ or more in the amount smoked between the two follow up visits.

For follow up, six groups were defined: continued heavy smokers, reducers (heavy smokers who had a reduction of at least $50 \%$ without quitting), continued light smokers, quitters, stable ex-smokers, and never smokers. Cox regression analysis was performed to calculate adjusted hazard ratios (HR). Compared with persistent heavy smokers, the HR for lung cancer in reducers was 0.73 (95\% confidence interval (CI) 0.54 to 0.98). For light smokers the HR was 0.44 (CI 0.35 to 0.56 ), for quitters 0.50 (CI 0.36 to 0.69 ), for stable exsmokers 0.17 (CI 0.13 to 0.23 ), and for never smokers 0.09 (CI 0.06 to 0.13 ).

The study shows that, in heavy smokers, smoking reduction by $50 \%$ or more significantly reduces the risk of lung cancer. However, the authors conclude that smoking cessation should still be advocated as reducing smoking has not been shown to decrease the risk of other smoking related disease.

D Rogers

SHO, Kettering General Hospital, Kettering, UK; dir11@doctors.org.uk 